\title{
NUMBER OF SERVICES PER CONSEPTION AND ITS RELATIONSHIP WITH DAIRY COW PRODUCTIVE AND REPRODUCTIVE TRAITS
}

\author{
Lāsma Cielava, Daina Jonkus, Līga Paura \\ Latvia University of Agriculture \\ lasma.cielava@1lu.lv
}

\begin{abstract}
The aim of our study was to determine up to what extent the number of services per calving (NSPC) affects dairy cow productive and reproductive performance. The study contains data from the Latvian Agricultural Data center about 26888 Latvian Brown (LB) and Holstein Black and White (HBW) breed cows that were born from year $2005-2010$, closed at least 5 full lactations and were culled from herds. In data set we have included data about cow milk productivity (calculated in ECM), longevity traits and reproduction traits. The reproduction traits included the number of services per conception (NSPC), calving interval (CI) and calving to conception interval (CCI) in the first five lactations. The average lifespan of LB and HBW dairy cows was 3149.5 days and in this period $39570.6 \mathrm{~kg}$ ECM were obtained. LB breed cows were characterized by 23.5 days longer lifespan and by $6035.4 \mathrm{~kg}$ ECM lower lifetime milk productivity than HBW breed cows, but they showed higher reproduction trait scores than LB breed group. HBW cows had a significantly $(\mathrm{p}<0.05)$ higher NSPC, CCI, number of milking days (MD) and CI than LB breed cows in all five analyzed lactations. The NSPC in the first lactation increased the calving age at the fifth lactation cows with NSPC in the first lactation > 4, fifth time calved 170.7 days in LB breed group and 190.8 days in HBW breed group later than cows with one NSPC in the first lactation.
\end{abstract}

Key words: milk productivity, longevity, reproductive traits.

\section{Introduction}

Dairy farming in Latvia historically plays an important role not only between different animal husbandry branches, but also in the whole agricultural field. To ensure the profitability of dairy farming and to keep the cost of milk production as low as possible, farmers need to pay attention not only to the possibilities of increasing the cow milk productivity, but also of preventing the problems that affect cow longevity and productivity (Hansen, 2000).

In an ideal situation, in a farm it would be possible from one cow in one year (365 days) obtain one viable calf (in the best situation - heifer), however, with the rapid increase of the level of productivity, often in farms arises a situation that the first service after calving is belated and in some cases it needs to be repeated. The increased number of services per conception often indicates the problems with cow reproductive system, which has a negative impact on farms profitability (LeBlanc, 2007; Honarvar et al., 2010) and often results in culling from herd (Sewalem et al., 2008). The diseases of reproductive system in different studies are named as one of main factors that affects the cow's lifespan, because the first from herds are culled cows that have problems with insemination (Wathes et al., 2008). The reproduction traits that give us an insight into herd's and cow's individual health condition is the number of services per conception (NSPC), calving to conception interval (CCI) and calving interval (CI).

The NSCP is affected by different external factors, for example, the content of ration and its suitability for cows physiological needs, the frequency of feeding (Butler, Pelton, \& Butler, 2006), housing system in the farm, season and weather conditions, the work quality of veterinary staff and the correct observation of heat (Nabenishi et al., 2011). It is particularly important to ensure that cows at the beginning of lactation receive ration with optimized amount of energy so they could prepare for starting a new pregnancy cycle. However, the internal factors, such as high milk productivity, the age of the cow and different health problems can affect not only NSCP, but also the length of CI (Bello, Stevenson, \& Tempelman, 2012; Dono et al., 2013).

For high yielding dairy cows, if they have some reproduction problems or diseases of reproductive system, milk productivity also decreases, which results in double losses from both - not acquired milk and the cow treatment expenses (Butler, Shaloo, \& Murphy, 2010; Galvćo et al., 2013; Giordano, Fricke, \& Cabarera, 2013).

The aim of our study was to determine up to what extent the number of services per calving (NSPC) affects the productive and reproductive performance of the dairy cows.

\section{Materials and Methods}

The data used in this study were obtained from the Latvian Agricultural Data center about Latvian Brown (LB) and Holstein Black and White (HBW) breed cows that were born from year 2005 to 2010 , closed at least 5 full lactations and were culled from herds. The data set included cows' milk productivity, longevity and fertility traits:

- milk productivity (milk yield, fat and protein content in full and standard lactation);

- longevity (date of birth and culling, number of milking days); 
- fertility traits (number of services per conception, calving to conception interval; calving interval).

To evaluate and compare the cow milk productivity, energy-corrected milk (ECM) was calculated using (1) formula:

ECM $=$ milkyield $\times$

$\times \frac{(0.383 \times \text { fatcontent },)+(0.242 \times \text { proteincontent },)+0.7832}{3.14}, k g$

From the cow's birth and culling dates their lifespan (LS) was calculated, and from Amount of ECM in each lactation lifetime milk productivity (LMP) was calculated. To characterize the economic benefit of the analyzed cows, average milk productivity in one life day (LDMP) was calculated:

$$
L D M P=\frac{L M P, k g}{L S, \text { days }}, k g E C M p e r d a y
$$

In the study, data about 26888 Latvian dairy cows (Table 1) were included. Cows were divided in four groups according to the number of services per conception (NSPC).

To determine the effect of factors on cow reproductive performance, factors were included in the following (3) model:

$\mathrm{Y}_{\mathrm{ijk}}=\mu+\mathrm{B}_{\mathrm{i}}+\mathrm{L}_{\mathrm{j}}+\mathrm{S}_{\mathrm{k}}+\mathrm{e}_{\mathrm{ijk}}$,

Where:

$\mathrm{Y}_{\mathrm{jik}}$ - observations of variable of interest; $\mu$ - underlying constant;
$\mathrm{B}_{\mathrm{i}}$ - fixed factor cow breed;

$\mathrm{L}_{\mathrm{j}}$ - fixed factor lactation;

$\mathrm{S}_{\mathrm{k}}$ - fixed factor NSCP in the first lactation;

$\mathrm{e}_{\mathrm{iklm}}$ - the random residual.

For the statistical analyses of influence of NSCP groups on the lifespan and lifetime milk productivity and reproductive performance, analysis of variance (ANOVA) was performed. Bonferroni pairwise comparison test was used to analyze the differences between NSCP factors groups' average values. In tables the average trait values were shown as least mean squares \pm standard errors. Differences were considered statistically significant when $\mathrm{p}<0.05$. Significant differences $(\mathrm{p}<0.05)$ in the tables were marked with different superscripted letters of alphabet (A, B, C, etc.). The mathematical processing was performed using the SPSS for Windows, version 15.

\section{Results and Discussion}

The lifespan and the amount of lifetime productivity are largely affected by their affiliation to the breed group. Latvian Brown (LB) breed cows belong to red breed group and, as it was determined in our previous studies, they are characterized by a longer lifespan, but lower lifetime and life day milk productivity than Holstein Black and White (HBW) breed cows (Cielava, Jonkus, \& Paura, 2014; 2015). For analyzed cows, the average lifespan was 3149.5 days in which $39570.6 \mathrm{~kg}$ of energy-corrected milk (ECM) were obtained that makes on average $12.6 \mathrm{~kg}$ ECM per one life day (Table 2).

The number of cows in different analyzed groups

\begin{tabular}{|c|c|c|c|}
\hline Trait & LB & HBW & LB+HBW \\
\hline N & 16404 & 10484 & 26888 \\
\hline \multicolumn{4}{|c|}{ NSCP in first lactation } \\
\hline 1 & 9534 & 5475 & 15009 \\
\hline 2 & 4087 & 2855 & 6942 \\
\hline 3 & 1661 & 1160 & 2821 \\
\hline$>4$ & 1122 & 994 & 2116 \\
\hline
\end{tabular}

Milk productivity and longevity traits of $\mathrm{LB}$ and $\mathrm{HBW}$ breed cows

\begin{tabular}{|l|c|c|c|c|}
\hline \multirow{2}{*}{\multicolumn{1}{|c|}{ Trait }} & \multicolumn{2}{c|}{ Breed } & \multirow{2}{*}{ Difference } & LB and HBW \\
\cline { 2 - 3 } & LB & HBW & $23.5^{*}$ & $3149.5 \pm 2.67$ \\
\hline LS, days & $3163.8 \pm 4.28$ & $3140.3 \pm 3.43$ & $6035.4^{*}$ & $39570.6 \pm 8.21$ \\
\hline LMP, kg ECM & $37217.3 \pm 84.25$ & $43252.7 \pm 105.39$ & $1.9^{*}$ & $12.6 \pm 0.02$ \\
\hline LDMP, kg ECM & $11.8 \pm 0.02$ & $13.7 \pm 0.03$ & \\
\hline
\end{tabular}

${ }^{*} \mathrm{p}<0.05 ; \mathrm{LS}$ - lifespan; LMP - lifetime milk productivity; LDMP - life day milk productivity. 


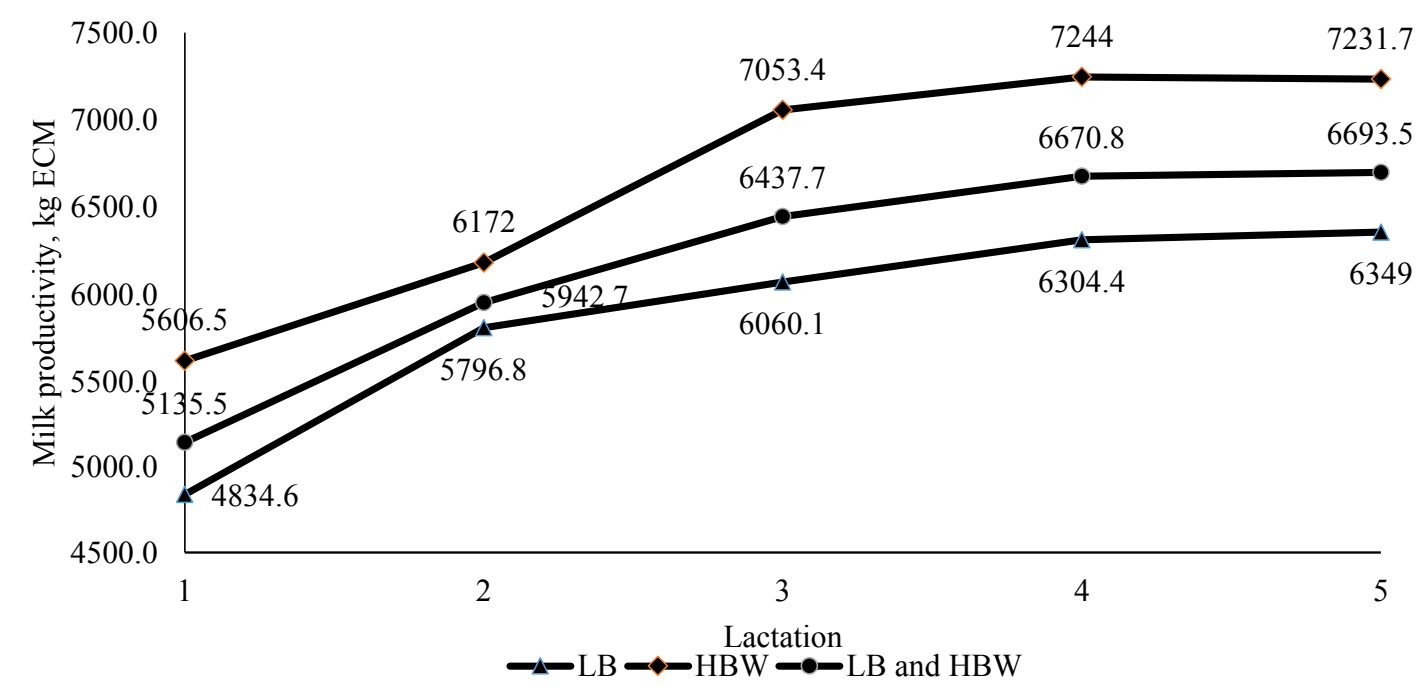

Figure 1. The average milk prductivity of $\mathrm{LB}$ and $\mathrm{HBW}$ cows from 1st to 5th lactation $\mathrm{ABCD}-$ milk productivity with different capital superscriptions differs significantly between lactations $(p<0.05)$.

In LB breed group, the cows lived on average 23.5 days longer than HBW breed cows, however, from LB cows in their life were obtained $6035.4 \mathrm{~kg} \mathrm{ECM}$ less than it was from HBW cows. The average milk productivity per one life day was significantly lower for LB breed cows (11.8 $\mathrm{kg}$ ECM for LB and $13.7 \mathrm{~kg}$ ECM from HBW cows, respectively).

The average milk productivity showed a tendency to gradually increase from $5135.5 \mathrm{~kg} \mathrm{ECM}$ in the first standard lactation to $6693.5 \mathrm{~kg}$ ECM obtained in the fifth lactation (Figure 1). The significant increase of milk productivity continued until the fourth lactation, after which such rapid productivity changes were not observed.

As determined previously, LB breed cows were characterized by lower milk productivity than HBW breed cows in life and they showed similar tendencies also by dividing milk productivity in different lactations. For HBW breed cows rapid increase of milk productivity was obtained from second to third lactation (+ $881.4 \mathrm{~kg} \mathrm{ECM} ; \mathrm{p}<0.05)$.

NSPC for the analyzed cows had a tendency to increase in each lactation (Table 3 ). In the first lactation the average NSPC was 1.76 times, which means that with the first service farmers impregnated $56.7 \%$ of serviced cows, but in the fifth lactation this indicator is significantly lower (on average 1.80 times) - with the first service impregnated $55.5 \%(\mathrm{p}<0.05)$ of serviced cows. One of the economically most important reproduction traits is $\mathrm{CCI}$, which is defined as the time period from the calving until the first successful service. This indicator is often used in connection with NSPC, because it depends on the necessity of repeated services, but from the results of other authors we can conclude that the length of CCI is determined also by the productivity of a cow, the balance of energy in ration (especially at the beginning of lactation) and health condition (Butler, Pelton, \& Butler, 2010).

The LB breed cows in the first and consequent lactations had a significantly lower NSPC than HBW breed cows (accordingly 1.71 and 1.86 in the first lactation) and it had a tendency to increase with the age of cows. In the fourth lactation for LB breed cows NSPC was 1.74, but the fourth lactation HBW breed cows were serviced 0.2 times more. Although 55.8\% of cows in the first lactation needed only one NSPC, there were $7.8 \%$ of cows that were serviced four times or more. CCI significantly longer were for HBW breed cows (128.3 days in the first and 138.5 days in the fourth lactation) and they were also characterized by highest milk productivity and NSPC, whereas in LB breed group the highest CCI were in the fourth lactation (123.8 days; $\mathrm{p}<0.05$ ).

With longer CCI, there is an impact on the number of milking days (MD) and length of CI in each lactation. From the length of $\mathrm{CI}$ we can make assumptions about the individual cow and herd reproductive health and about the cow's efficiency in herd (Pryce et al., 2004; Bujko et al., 2013). For analyzed cows, the average CI was 399.6 days long (from the third to fourth lactation for LB breed cows) to 407.3 days long (from the fourth to fifth lactation for HBW breed cows), furthermore, LB breed cows in all lactations had shorter CI than HBW breed cows. The reasoning behind the higher average reproduction trait values could be HBW breed's higher milk productivity in all lactations which can lead to lower pregnancy rates in this group that results in longer CCI and CI periods (Riecka \& Candrák, 2011; Arbel et al., 2001). NSPC in the first lactation is a factor that affects not only the length of $\mathrm{CCI}$ and $\mathrm{CI}$ periods, but it is also one of factors that influences NSPC in cow's later life (Figure 2). 
Reproduction traits in different lactations of LB and HBW breed cows

Table 3

\begin{tabular}{|c|c|c|c|c|}
\hline Lactation & NSPC & $\mathrm{CCI}$ & MD & $\mathrm{CI}$ \\
\hline \multicolumn{5}{|c|}{ LB and HBW (N=26888) } \\
\hline $1 \rightarrow 2$ & $1.76 \pm 0.01^{\mathrm{A}}$ & $120.5 \pm 0.46^{\mathrm{A}}$ & $341.0 \pm 0.43^{\mathrm{A}}$ & $400.9 \pm 0.45^{\mathrm{A}}$ \\
\hline $2 \rightarrow 3$ & $1.78 \pm 0.14^{\mathrm{AB}}$ & $119.9 \pm 0.44^{\mathrm{A}}$ & $337.2 \pm 0.42^{\mathrm{B}}$ & $400.2 \pm 0.44^{\mathrm{A}}$ \\
\hline $3 \rightarrow 4$ & $1.77 \pm 0.07^{\mathrm{A}}$ & $121.9 \pm 0.45^{\mathrm{A}}$ & $337.5 \pm 0.44^{\mathrm{B}}$ & $399.6 \pm 0.48^{\mathrm{A}}$ \\
\hline $4 \rightarrow 5$ & $1.80 \pm 0.07^{\mathrm{B}}$ & $129.5 \pm 0.48^{\mathrm{B}}$ & $344.3 \pm 0.46^{\mathrm{A}}$ & $407.3 \pm 0.51^{\mathrm{B}}$ \\
\hline \multicolumn{5}{|c|}{ LB $(N=16404)$} \\
\hline $1 \rightarrow 2$ & $1.71 \pm 0.01^{\mathrm{Aa}}$ & $115.3 \pm 0.59^{\mathrm{Aa}}$ & $335.9 \pm 0.56^{\mathrm{Aa}}$ & $396.4 \pm 0.59^{\mathrm{Aa}}$ \\
\hline $2 \rightarrow 3$ & $1.70 \pm 0.01^{\mathrm{ABa}}$ & $114.4 \pm 0.58^{\mathrm{Aa}}$ & $331.4 \pm 0.53^{\mathrm{Ba}}$ & $395.5 \pm 0.57^{\text {Аа }}$ \\
\hline $3 \rightarrow 4$ & $1.70 \pm 0.01^{\mathrm{ABa}}$ & $116.4 \pm 0.58^{\mathrm{Aa}}$ & $332.3 \pm 0.54^{\mathrm{Ba}}$ & $397.4 \pm 0.58^{\text {Aa }}$ \\
\hline $4 \rightarrow 5$ & $1.74 \pm 0.01^{\mathrm{Ba}}$ & $123.8 \pm 0.63^{\mathrm{Ba}}$ & $337.7 \pm 0.58^{\mathrm{Aa}}$ & $404.7 \pm 0.62^{\mathrm{Ba}}$ \\
\hline \multicolumn{5}{|c|}{ HBW $(\mathrm{N}=10484)$} \\
\hline $1 \rightarrow 2$ & $1.86 \pm 0.01^{\mathrm{Ab}}$ & $128.3 \pm 0.70^{\mathrm{Ab}}$ & $349.9 \pm 0.70^{\mathrm{ABb}}$ & $409.2 \pm 0.74^{\mathrm{Ab}}$ \\
\hline $2 \rightarrow 3$ & $1.90 \pm 0.01^{\mathrm{Bb}}$ & $128.2 \pm 0.24^{\mathrm{Ab}}$ & $346.1 \pm 0.67^{\mathrm{Ab}}$ & $409.1 \pm 0.71^{\mathrm{Ab}}$ \\
\hline $3 \rightarrow 4$ & $1.92 \pm 0.01^{\mathrm{Bb}}$ & $130.6 \pm 0.73^{\mathrm{ABb}}$ & $346.1 \pm 0.67^{\mathrm{Ab}}$ & $411.5 \pm 0.73^{\mathrm{ABb}}$ \\
\hline $4 \rightarrow 5$ & $1.94 \pm 0.01^{\mathrm{Bb}}$ & $138.5 \pm 0.79^{\mathrm{Bb}}$ & $353.4 \pm 0.72^{\mathrm{Bb}}$ & $419.3 \pm 0.78^{\mathrm{Bb}}$ \\
\hline
\end{tabular}

${ }_{\mathrm{AB}}$ - capital letters in superscription denote significant differences between lactations $(\mathrm{p}<0.05)$; ${ }^{\mathrm{ab}}-$ traits with different superscriptions differ between breeds $(\mathrm{p}<0.05)$ NSPC - number of services for conception; CCI - calving to conception, days; MD - milking days; $\mathrm{CI}$ - calving interval

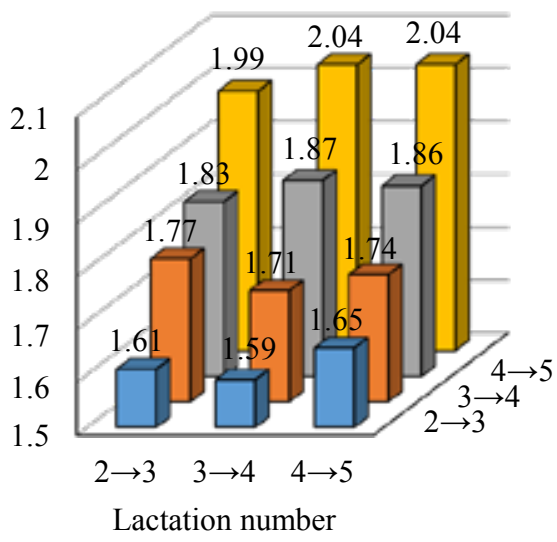

LB

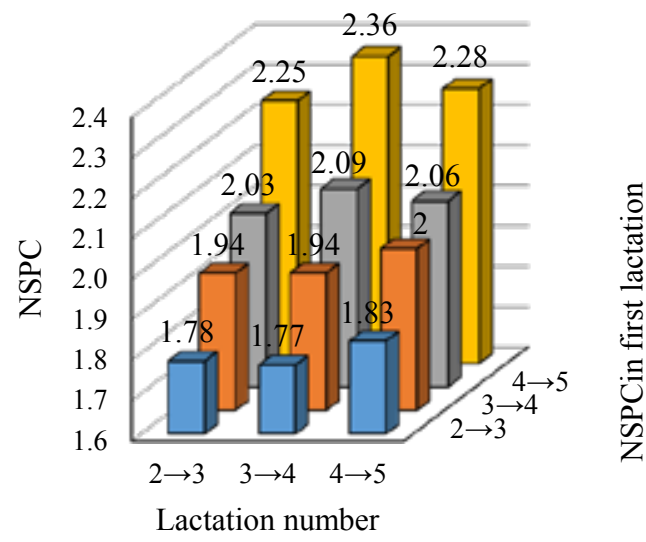

HBW

Figure 2. Average number of services to one conception for LB and HBW breed cows with different NSPC in the first lactation (LB - Latvian Brown; HBW - Holstein Black and White; NSPC - number of services per calving)

$\mathrm{ABCD}$ - traits with different capital superscriptions differ significantly between NSPC groups in one lactation $(\mathrm{p}<0.05)$; abc - traits with different superscriptions differ between lactations $(\mathrm{p}<0.05)$.

LB breed cows in all study groups had lower consecutive NSPC than HBW breed cows. The maximal NSPC (2.04 times per one calving) in LB breed group were in the third and fourth lactation for cows that in the first lactation were serviced four or more times, whereas HBW breed cows needed accordingly 2.36 and 2.28 services in the same groups. In LB breed cows, which in the first lactation were serviced one time, in the consecutive lactations were observed having significantly lower NSPC (1.61 in the second and 1.65 in fourth lactation). The similar tendency occurred in HBW breed group, but the average NSPC in each group was higher than that for LB breed cows. Studies show that the breed of cows and cow milk productivity are the main factors that show the biggest impact on NSPC in different lactations, because of the tendency to repeat service for cows with higher milk productivity (Cummins et 


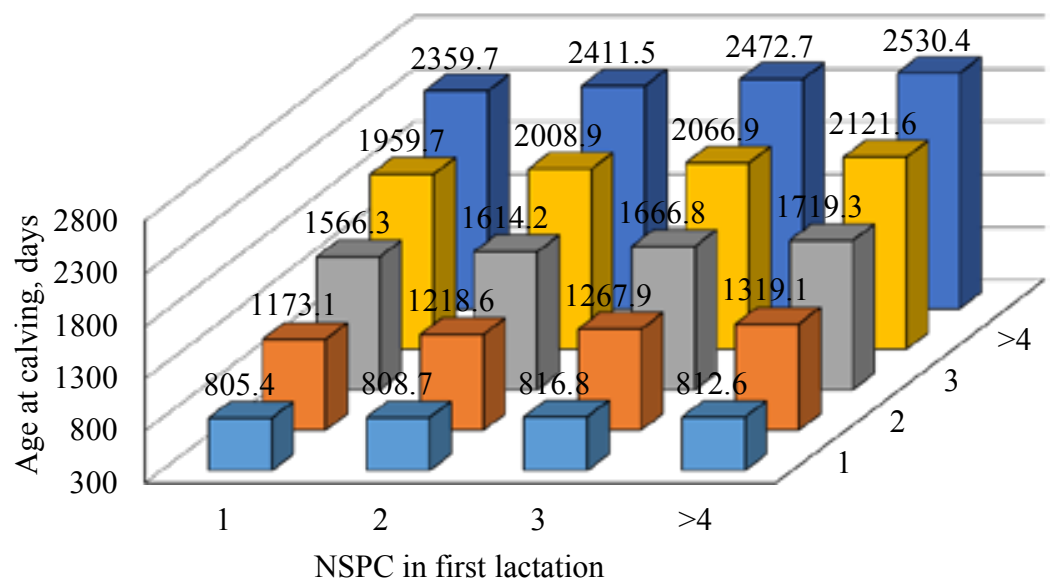

Figure 3. The average calving age at different lactations depending from number of services per calving (NSPC) in first lactation for LB breed cows;

ABCD - traits with different capital superscriptions differs significantly between NSPC groups $(\mathrm{p}<0.05)$

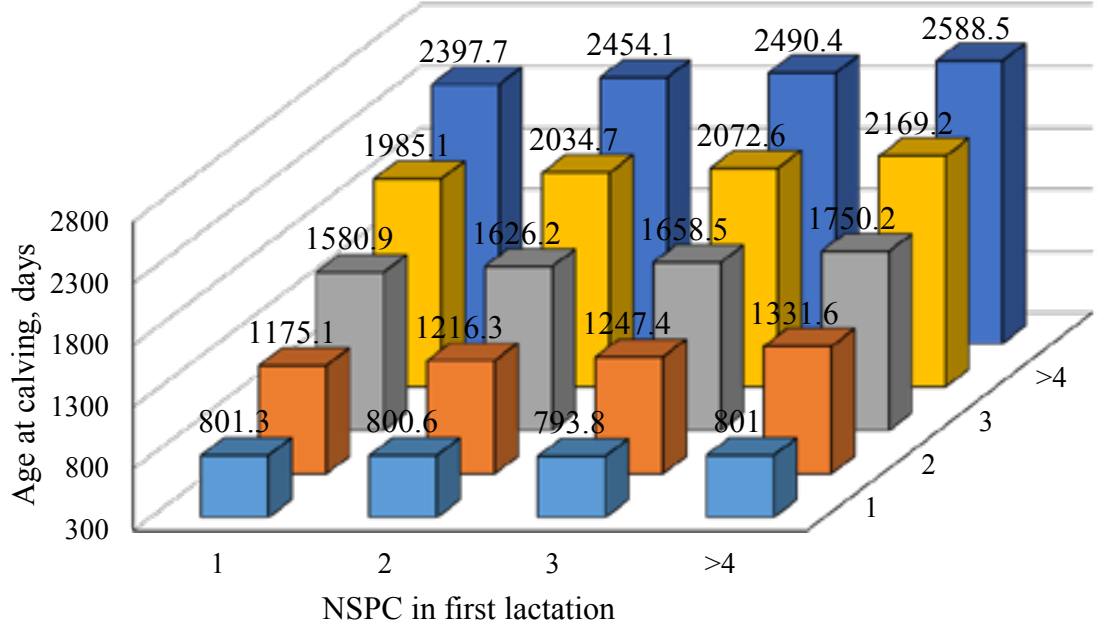

Figure 4. The average calving age at different lactations depending from number of services per calving (NSPC) in first lactation for HBW breed cows;

$\mathrm{ABCD}$ - traits with different capital superscriptions differs significantly between NSPC groups $(\mathrm{p}<0.0)$

al., 2012; Bujko et al., 2013). The main environmental factor that affects NSPC is the heat detection system in the farm. If heat detection is done properly and insemination process follows with a good execution, it can improve the effectivity of insemination (Wall et al., 2003)

The NSPC in the first lactation and its effect on the calving age in consecutive lactations is given in Figure 3. In LB breed group there were no statistically significant differences between cow ages at the first calving in different NSPC at first lactation groups. But in the second time cows that in the first lactation were serviced one time calved 146.0 days earlier than cows that needed four or more services in the first lactation (1173.1 and 1319.1 days, respectively). LB breed cows that in the first lactation were serviced four or more times at the beginning of fifth lactation were 170.7 days older than cows that in the first lactation were inseminated with one service.

In HBW breed group a similar tendency was observed where with the increase of NSPC in the first lactation also increased the age of cows at the beginning of consecutive lactations (Figure 4).

Analyzed HBW breed cows had the highest milk productivity, not only in lactation, but also in one life day, which could serve as the main factor for poorer reproductive traits in comparison with LB breed cows. A similar tendency was observed in the LB breed group, where there were no significant differences between ages of first calving in each NSPC group. In the second lactation, between calving ages of cows in the first and fourth group appeared difference of 156.6 
days and in the fifth lactation it increased to 190.8 days. HBW cows in comparison with LB breed cows had the oldest calving age at the fifth calving and it amounted to 58.1 days in the group with NSPC four or more.

\section{Conclusions}

For Latvian Brown and Holstein Black and White cow breed groups, the number of services per conception showed a significant $(\mathrm{p}<0.05)$ effect on their reproductive traits in consecutive and later lactations. With the increase of number of services per conception in the first calving came the increase of age at the calving in later lactations, which lowers the number of potential lactations in the cow's life and also points to the problems connected with the reproductive performance in farms. In the further studies there is a need to make deeper research in the relationships between different cow production and reproduction traits and about the factors that affect the productive and reproductive performance in herds.

\section{References}

1. Arbel, R., Bigun, Y., Ezra, E., Sturman, H., \& Hojman, D. (2001). The effect of extended calving intervals in high-yielding lactating cows on milk production and profitability. Journal of Dairy Science, 84, $600-$ 608. DOI: 10.3168/jds.S0022-0302(01)74513-4.

2. Bello, N.M., Stevenson, J.S., \& Tempelman, R.J. (2012). Invited review: Milk production and reproductive performance: Modern interdisciplinary insights into an enduring axiom. Journal of Dairy Science, 95, 5461 - 5475. DOI: $10.3168 /$ jds.2012-5564.

3. Bujko, J., Candrák, J., Strapák, P., Žitný, J., \& Hrnčár, C. (2013). The Association between Calving Interval and Milk Production traits in population of dairy cows of Slovak Simmental cattle. Animal Science and Biotechnologies. 46 (2), 53 - 57. DOI: 10.4236/oalib.1101342.

4. Butler, S.T., Shalloo, L., \& Murphy, J.J. (2010). Extended lactations in a seasonal-calving pastoral system of production to modulate the effects of reproductive failure. Journal of Dairy Science, 93, $1283-1295$. DOI: $10.3168 /$ jds.2009-2407.

5. Butler, S.T., Pelton, S.H., \& Butler, W.R. (2006). Energy balance, metabolic status, and the first postpartum ovarian follicle wave in cows administered propylene glycol. Journal of Dairy Science, 89, 2938 - 2951. DOI: $10.3168 /$ jds.S0022-0302(06)72566-8.

6. Cielava, L., Jonkus, D., \& Paura, L. (2014). Effect of farm size on the productivity and longevity of Latvian Brown cows. Research for rural development 2014: annual 20th international scientific conference proceedings. 1, $95-99$.

7. Cielava, L., Jonkus, D., \& Paura, L. (2015). Analysis of factors affecting length of productive life of Latvian brown cows breed Book of abstracts of the 66th annual meeting of the European Association for Animal Production "Innovation in livestock production: from ideas to practice". 21, 405.

8. Cummins, S.B., Lonergan, P., Evans, A.C.O., Berry, D.P., Evans, R.D., \& Butler, S.T. (2012). Genetic merit for fertility traits in Holstein cows: I. Production characteristics and reproductive efficiency in a pasture-based system. Journal of Dairy Science, 95, 1310 - 1322. DOI: 10.3168/jds.2011-4742.

9. Dono, G., Giraldo, L., \& Nazzaro, E. (2013). Contribution of the calving interval to dairy farm profitability: results of a cluster analysis of FADN data for a major milk production area in southern Italy. Spanish Journal of Agricultural Research. 11, 857 - 868. DOI: 10.5424/sjar/2013114-3873.

10. Galvćo, K.N., Federico, P., De Vries, A., \& Schuenemann, G.M. (2013). Economic comparison of reproductive programs for dairy herds using estrus detection, timed artificial insemination, or a combination. Journal of Dairy Science, 96, 2681 - 2393. DOI: 10.5424.

11. Giordano, J.O., Fricke, P.M., \& Cabrera, V.E. (2013). Economics of resynchronization strategies including chemical tests to identify non-pregnant cows. Journal of Dairy Science, 96, $949-961$.

12. Hansen, L.B. (2000). Consequences of selection for milk yield from a geneticist's viewpoint. Journal of Dairy Science, 83, 1145 - 1150. DOI: 10.3168/jds.S0022-0302(00)74980-0.

13. Honarvar, M., Nejati Javaremi, A., Miraei Ashtiani, S.R., \& Dehghan Banadaki, M. (2010). Effect of length of productive life on genetic trend of milk production and profitability: A simulation study. African Journal of Biotechnology. 9, 3000 - 3010. DOI: 10.5897/AJB2010.000-3135.

14. LeBlanc, S. (2007). Economics of improving reproductive performance in dairy herds. WCDS Advances in Dairy Technology 19. 201 - 214. DOI: 10.1016/j.theriogenology.2010.04.008.

15. Nabenishi, H., Ohta, H., Nishimoto, T., Morita, T., Ashizawa, K., \& Tsuzuki, Y. (2011). Effect of the temperature-humidity index on body temperature and conception rate of lactating dairy cows in southwestern Japan. Journal of Reproduction and Development, 57(4), 450 - 456. DOI: 10.1262/jrd.10-135T. 
16. Pryce, J.E., Royal, M.D., Garnsworthy, P.C., \& Mao, I.L. (2004). Fertility in the high-producing dairy cow. Livestock production science, 86(1), 125 - 135. DOI: 10.1016/S0301-6226(03)00145-3.

17. Riecka, Z., \& Candrák, J. (2011). Analysis of relationship between production and reproduction traits of Holstein cattle population in the Slovak Republic. Scientific Papers Faculty of Animal Sciences and Biotechnologies, Timisoara. 44(1), 332 - 336.

18. Sewalem, A., Miglior, F., Kistemaker, G.J., Sullivan, P., \& Van Doormaal, B.J. (2008). Relationship between reproduction traits and functional longevity in Canadian dairy cattle. Journal of Dairy Science, 91. 1660 - 1668. DOI: 10.3168/jds.2007-0178.

19. Wall, E., Brotherstone, S., Wooliams, J.A., Banos, G., \& Coffey, M.P. (2003). Genetic evaluation of fertility using direct and correlated traits. Journal of Dairy Science, 86, 4093 - 4102. DOI: 10.3168/jds. S0022-0302(03)74023-5.

20. Wathes, D.C., Brickell, J.S., Bourne, N.E., Swali, A., \& Cheng, Z. (2008). Factors influencing heifer survival and fertility on commercial dairy farms. Animal Science. 8, 1135 - 1143. DOI: 10.1017/ S1751731108002322. 